\title{
BMJ Open Qualitative evaluation of an educational intervention to reduce medicolegal risks for medical doctors experiencing significantly more cases than their peers in the UK and Ireland
}

\author{
John Jolly, ${ }^{1}$ Paul Bowie, ${ }^{2}$ Julie Price, ${ }^{1}$ Matt Mason, ${ }^{1}$ Mark Dinwoodie ${ }^{1}$
}

To cite: Jolly J, Bowie P, Price J, et al. Qualitative evaluation of an educational intervention to reduce medicolegal risks for medical doctors experiencing significantly more cases than their peers in the UK and Ireland. BMJ Open 2018;8:e020838. doi:10.1136/ bmjopen-2017-020838

- Prepublication history and additional material for this paper are available online. To view these files, please visit the journal online (http://dx.doi. org/10.1136/bmjopen-2017020838).

Received 27 November 2017 Revised 12 January 2018 Accepted 23 January 2018

Check for updates

${ }^{1}$ Medical Protection Society, Leeds, UK

${ }^{2}$ Institute of Health and Wellbeing, University of Glasgow, Glasgow, UK

Correspondence to Dr Paul Bowie; pslhumanfactors@gmail.com

\section{ABSTRACT}

Objectives The Medical Protection Society (MPS) is a leading protection organisation for healthcare professionals worldwide. In the UK and Ireland, a small minority of MPS members experience significantly more medicolegal cases than their peers and are invited to participate in a risk education (RE) remediation process. To understand more about this educational intervention, we sought to explore participating doctors' views of their experiences of this process and identify self-reported performance improvements and what elements of the intervention could be improved.

Design Qualitative semistructured telephone interviews with a convenience sample of doctors with significantly more medicolegal cases than their peers identified by MPS.

Setting UK and Ireland MPS members.

Participants A convenience sample of 20 general medical practitioners and hospital specialists from a total of 79 who completed the RE process $(25.3 \%$ response rate), with a particular focus on the Member Risk Review programme, between November 2013 and October 2015. Results 19 participants were male and 16 were based in general medical (office) practice. Three key themes were generated: personal and professional impacts and actions (eg, member has taken action to reduce clinical workload); comprehension and validity of RE interventions (eg, risks were related to wider patient management); and feedback and proposals (eg, the supportive nature of the educational interventions should be clear from the start). A number of recommendations were made by participants to improve the RE process and enhance the educational experience. Conclusions The RE process was largely valued by participants with many reporting that participation led to some positive professional behaviour changes and improvements in practice processes and personal well-being.

\section{INTRODUCTION}

Medical underperformance is a cause for concern among patients, policymakers, regulators and educators in healthcare settings worldwide. In the UK, around 5 per 1000 doctors are referred annually to the national
Strengths and limitations of this study

- The doctors were interviewed at least 6 months after the intervention and were able to report changes/ transitions in their behaviours and circumstances, but recall bias may also have been an issue.

- A qualitative approach using semistructured telephone interviews provides potentially greater insights into experiences and views of this type of educational programme and reported impacts on change and improvement that may occur.

- A limited participation rate was achieved and so a pragmatic convenience sample was recruited; therefore, response bias is likely as this may not adequately reflect the characteristics and experiences of all those doctors who completed the programme.

- It is possible that participants felt they had to report completion of recommended improvement actions due to the nature of the interview or implications with future contact with Medical Protection Society.

- It was difficult to determine if change or transition was explicitly linked to the risk education process.

clinical performance assessment service, ${ }^{1}$ while in 2015, the General Medical Council (GMC; UK medical regulator) investigated 2233 complaints about doctors' fitness to practice. $^{2}$ An Australian study of healthcare complaints found that $3 \%$ of the medical workforce accounted for $49 \%$ of all complaints received by the health service ombudsman, with around $1 \%$ of doctors responsible for one quarter. ${ }^{3}$ Similarly, a US study of 66426 paid claims found approximately $1 \%$ of all doctors accounted for $32 \%$ of them. ${ }^{4}$ A Medical Protection Society (MPS) survey of 600 general practitioner (GP) members found that $35 \%$ of survey respondents had received a claim for clinical negligence during their medical career. Of those who had received a claim, 39\% received it in the last 2 years. ${ }^{5}$ 
A range of physical and psychological impacts are apparent for all concerned. For patients (and families), this will typically include avoidable harm, dissatisfaction with care, emotional upset, irritation and inconvenience. ${ }^{1}$ Care provider organisations may suffer poor reputational risk, increased disruption and workloads. ${ }^{36}$ For the doctors involved, this may lead to significant distress, restricted freedom for clinical practice, inconvenience related to educational assessment and further professional development and difficult working environments for colleagues and other care providers. ${ }^{6-10}$ Finally, health service providers, doctors and professional indemnity organisations may all be affected by increasing financial costs. $^{136-10}$

The nature of claims, complaints, regulatory referrals and disciplinary matters also suggests they are highly skewed and often focused on small groups of doctors 'who have identifiable characteristics'. ${ }^{141-16}$ For example, studies of doctors who have experienced multiple malpractice claims, complaints or disciplinary action compared with those with few or none have highlighted differences in age, gender, seniority, specialty attachment and those working longer hours and at a late career stage. ${ }^{1718}$

Among patients, care providers, regulators and the public, there is increasing attention to medical underperformance. Closer scrutiny of GPs has revealed significant educational needs for some. ${ }^{19}$ Identifying and remediating those doctors whose performance gives cause for concern is critical for care quality and safety. ${ }^{20}{ }^{21}$ The underlying nature of poor performance among hospital specialists and family doctors is established as being multifaceted $^{22}$ and, among other factors, includes poor communication skills and relationships with colleagues, inadequate practice arrangements, practising beyond skills or knowledge and unsafe medication prescribing.

Medical remediation of doctors refers to a complex process of addressing performance concerns (knowledge, skills and behaviours). It is an umbrella term for all activities that provide help: from the simplest advice, to formal mentoring, further training, reskilling and rehabilitation. It may also involve pragmatic solutions to restrict the full scope of medical practice, without unduly compromising patient safety or the physical and psychosocial well-being of the doctors concerned. ${ }^{23}{ }^{24}$ Swanwick and Whiteman ${ }^{25}$ outline four inter-related areas that often give rise to the complex performance concerns of doctors and that may need to be addressed simultaneously, either individually or collectively, as part of any intervention: health (biopsychosocial), clinical competence,personality and behaviour and organisational context. However, how medical underperformance (and, therefore, remediation per se) is identified and successfully managed is acknowledged to be limited and in need of comprehensive research. ${ }^{21}$ A recent systematic review has highlighted the remediation challenge and that most related interventions were tailored for undergraduate education, with limited evidence for what works and why at postgraduate training level and beyond. ${ }^{26}$
The MPS is a leading mutual, not-for-profit membership organisation. ${ }^{27}$ It protects and supports the professional interests of more than 300000 members around the world. Membership provides access to expert advice and support together with the right to request indemnity for complaints or claims arising from professional practice. In the UK, MPS manages claims for clinical negligence brought against members who are GPs and private doctors, while the National Health Service (NHS) Litigation Authority manages claims arising in the NHS hospital sector.

Our approach to risk carefully balances the needs of the individual member with those of the membership as a whole. MPS is well aware of the potential impact that claims and regulatory proceedings can have on a member's career and believe that prevention is better than cure. The aim is to alert members when their risk profile differs from that of their peers and work with them to reduce their risk.

Medical doctors with significantly more medicolegal cases than their peers are identified by MPS. Following a review of the individual's case experience by the senior education team, doctors are selected to participate in the risk education (RE), which is a remediation process based on educational development principles. Doctors with medicolegal cases arising from their work in NHS hospitals, not covered by MPS indemnity, are not selected for this remediation programme. The particular circumstances common to these doctors include system risks as identified from MPS data relating to their reported medicolegal cases. A description of the selection process is provided (see online supplementary file $1)$.

Against this background, the aim of this study was to explore doctors' views of their experiences of the RE intervention.

Our objectives were as follows:

- to better understand the perceived strengths and limitations of the RE interventions as experienced by participants

- to explore and describe self-reported performance improvements (eg, changed attitudes or modified behaviours) associated with the intervention.

- to solicit feedback from participants on what elements of the intervention and process could be improved.

\section{METHODS}

\section{Context: RE interventions}

$\mathrm{RE}$ is a tailored plan of educational programmes for medical doctors identified by MPS as having significantly more cases than their peers. The programmes have been developed for more than 10 years and draw on organisational expertise in medicolegal, dentolegal, education and risk matters. Three core interventions are provided as part of RE (box 1), all of which are focused on the areas MPS feel are likely to achieve the greatest impact in reducing medicolegal risks: Member Risk Review (MRR), Clinical Communication Programme (CCP) and Communication or Risk Management Workshops. 


\section{Box 1 Core MPS risk education (RE) interventions}

\section{Member Risk Review (MRR)}

MRR is a risk identification process to assist in identifying existing and potential risks and to make recommendations and suggest remedial action. Clinicians can reflect on the cases opened by MPS and identify learning points. The process relates primarily to the organisational context and biopscychosocial aspects of educational remediation principles. It involves a 4-hour visit to the clinician's place of work (eg, GP practice) or MPS office by an experienced and accredited clinical risk facilitator. Based on these discussions, the facilitator produces a related risk report including suggested recommended actions.

\section{Clinical Communication Programme (CCP)}

The CCP is an intensive programme worth 40 hours of continuing professional development undertaken over a $24-$ week period. The CCP is undertaken when there is evidence of communication, manner or attitude problems on the case summaries. The CCP focuses on addressing the communication behaviour and helping to achieve some attitudinal change to improve performance.

\section{Communication or Risk Management Workshops (CRMWs)}

The 3-hour workshops are designed to improve reflection upon clinical interactions and to enhance doctor and patient satisfaction. Three workshops are designed to master communication skills in shared decision making, managing adverse outcomes and managing individual risk. Two workshops are designed to improve medical records for GPs and safer prescribing practices.

In this study, the primary recruitment focus was those doctors who had participated in a review of system risks with recommended remedial actions-the MRR. However, all participants will also have been involved in one or more of the other core RE interventions. We know from previous MPS CCP research that the numbers of claims against participants were reduced following undertaking the intervention. ${ }^{28}$ It was important for MPS to understand better the strengths and areas of improvement of the MRR. By focusing on the MRR as the primary recruitment, this increased the proportion of general medical practitioners in the eligible sample.

The lead study researcher (JJ), who is a senior medical doctor and educator, led the study and conducted the telephone interviews. JJ joined MPS after the time when the participants were involved in the RE process. The doctors interviewed were informed of this. The second author (PB) was contracted by MPS to provide independent research expertise. To validate findings, a third colleague (JP) read the transcripts and cross-checked the theme generation against the coding and categorisation process. JP, MM and MD were involved in the MPS RE process at the time.

\section{Settings and participant recruitment}

Seventy-nine GPs and consultants undertaking private practice based in England, Scotland, Wales and Ireland participated in and completed the MRR educational programme. Between April and June 2016, each doctor was sent an information sheet about the aims of the evaluation and asked if they would voluntarily participate. A convenience sample of 20 doctors expressed an interest, and all were selected to participate.

\section{Data collection}

Data were collected via semistructured telephone interviews $^{29}$ conducted during April-July 2016 by the lead researcher (JJ), who is a senior medical doctor and educator who was independent of the RE process. The interviewees had participated in the MRRs between November 2013 and October 2015. A completed Central Office for Research Ethics Committees (COREC) checklist for reporting qualitative studies is provided in online supplementary file 2, and a logic model for guiding this evaluation is illustrated in online supplementary file 3 . The interviews were guided by (but not constrained by) a flexible interview topic guide to enable a fuller range of participants' views and experiences to be captured, with no new insights emerging after interview number 15 suggesting that data saturation was reached (online supplementary file 4 ). The guide was flexibly designed to explore participant perceptions and experiences together with facilitators and inhibitors related to the RE programme.

Interviews were audio-recorded and digitally transcribed (in a way that protects anonymity) with the consent of participants. Contemporaneous field notes were also taken during each discussion. Transcripts were checked against the tape recordings for accuracy and errors by the interviewer (JJ). The mean time taken for interviews was $50 \mathrm{~min}$, with a range between $26 \mathrm{~min}$ and $85 \mathrm{~min}$. All data were organised and managed using an Excel spread sheet.

The specific study methods employed were pragmatic and justified in terms of feasibility, particularly when compared with the costs, time and geography factors that would be involved in using alternative methods (eg, face-to-face interviews or focus groups). Additionally, all participants are busy working clinicians, which was an added challenge regardless of qualitative method employed.

\section{Data analysis}

A thematic analysis ${ }^{30}$ of interview transcripts was conducted independently by two authors (IJ and PB). Both carefully

\begin{tabular}{|c|c|}
\hline Characteristic & $n=20, n(\%)$ \\
\hline \multicolumn{2}{|l|}{ Gender } \\
\hline Male & $19(95)$ \\
\hline Female & $1(5)$ \\
\hline \multicolumn{2}{|l|}{ Age } \\
\hline Median: 50.5 years & Range: $38-68$ years \\
\hline \multicolumn{2}{|l|}{ Medical specialty } \\
\hline General practice & $16(80)$ \\
\hline Trauma and orthopaedics & $2(10)$ \\
\hline General surgery & $1(5)$ \\
\hline Urology & $1(5)$ \\
\hline
\end{tabular}


Table 2 Break down of the number of risk education (RE) programmes completed by participating study doctors

\section{Risk education workshops}

\begin{tabular}{|c|c|c|c|c|c|c|c|}
\hline \multirow[b]{2}{*}{$\begin{array}{l}\text { Participant } \\
\text { ID }\end{array}$} & \multirow[b]{2}{*}{ MRR } & \multirow[b]{2}{*}{ CCP } & \\
\hline & & & $\begin{array}{l}\text { Medical records } \\
\text { for GPs }\end{array}$ & $\begin{array}{l}\text { Mastering adverse } \\
\text { outcomes }\end{array}$ & $\begin{array}{l}\text { Mastering shared } \\
\text { decision making }\end{array}$ & $\begin{array}{l}\text { Medication } \\
\text { errors and safer } \\
\text { prescribing }\end{array}$ & $\begin{array}{l}\text { Mastering } \\
\text { your risk }\end{array}$ \\
\hline 1 & $x$ & $x$ & $x$ & $x$ & $x$ & - & \\
\hline 7 & $x$ & - & $x$ & $x$ & - & - & \\
\hline 14 & $x$ & $x$ & $x$ & $x$ & $x$ & $x$ & \\
\hline 16 & $\mathrm{X}$ & $x$ & - & $x$ & $x$ & - & \\
\hline 17 & $x$ & $x$ & - & $x$ & $x$ & $x$ & \\
\hline 18 & $x$ & $x$ & $x$ & $x$ & $x$ & $x$ & \\
\hline 28 & $x$ & - & $x$ & $x$ & - & - & $x$ \\
\hline 29 & $x$ & - & - & - & - & $x$ & - \\
\hline 31 & $x$ & - & $x$ & $x$ & - & $x$ & $x$ \\
\hline 33 & $x$ & $x$ & - & $x$ & $x$ & - & - \\
\hline 34 & $x$ & - & - & $x$ & $x$ & - & - \\
\hline 35 & $x$ & $x$ & $x$ & $x$ & $x$ & - & - \\
\hline 36 & $x$ & $x$ & - & $x$ & $x$ & - & - \\
\hline 39 & $\mathrm{X}$ & - & - & $x$ & $x$ & - & - \\
\hline 51 & $x$ & - & $x$ & - & - & - & - \\
\hline 53 & $x$ & - & - & - & - & - & - \\
\hline 54 & $x$ & $x$ & - & $x$ & $x$ & - & - \\
\hline 60 & $x$ & $x$ & - & $x$ & $x$ & - & - \\
\hline 64 & $x$ & $x$ & - & $x$ & $x$ & - & - \\
\hline 77 & $x$ & $x$ & - & $x$ & $x$ & - & - \\
\hline Total (n, \%) & 20 & 12 & 8 & 17 & 14 & 5 & 2 \\
\hline
\end{tabular}

CCP, Clinical Communication Programme; MRR, Member Risk Review; X, completed.

read and reread transcripts and then coded and categorised data on an iterative basis. They met to compare data analyses and generate themes (by merging, adding to or deleting existing categories), with any disagreements resolved by discussion and debate until consensus was reached. To validate findings, a third colleague (JP) read the transcripts and cross-checked the theme generation against the coding and categorisation process. A one-page high-level summary of the study findings was sent to all participants 4 weeks after the interview process had ended to provide an opportunity to query the data interpretation and add further comments. No feedback was received from any participants.

\section{RESULTS}

Study participants: characteristics, related cases and RE interventions completed

A total of 20 doctors from a possible 79 who completed the $\mathrm{RE}$ responded and were recruited for interview $(25.3 \%)$. Of the 20 participating doctors, 19 were male (95\%), 9 were aged between 41 and 50 years (45\%), 10 were aged 51 years or older $(50 \%)$ and 16 were based in general medical practice $(80 \%)$. Further details of the characteristics of participants are outlined in table 1 , while a break down of the RE interventions completed by each doctor is described in table 2.

The interview data analysis and interpretation led to the generation of the following three themes: personal and professional impacts and actions; comprehension and validity of RE interventions; and feedback and proposals. Details of each theme, linked categories and supporting quotations are outlined in table 3 .

\section{Personal and professional impacts and actions}

By completing the MPS-recommended key actions, the aim was for the doctors to improve safety, quality of care provided and to reduce their risk of further medicolegal cases. Participants reported that they had completed the majority of the key recommended actions (tables 4 and 5), although some were yet to be completed. For some actions the doctors did not know if the key recommendation had been completed. The most common reasons were that they were uncertain if the actions were completed by someone else, for example, the practice manager. One GP had relocated since participation in the RE process and so some of the recommendations were no longer relevant.

Some who had participated in RE over 12 months prior to the interview were able to put forward views on how 
Table 3 Details of each result theme, linked categories, theory and supporting quotations.

\section{Theme (categories)}

1. Personal and professional impacts and actions

- behavioural change in personal work circumstances linked to MRR

- action on MRR recommendations made

- behavioural change linked to the Clinical Communication Programme (CCP)

- recognised benefits following changes

- changes in personal and professional circumstances/contexts since MRR

\section{Selected verbatim quote}

'The change of my attitude, not only to look at myself, my feelings, I think the best is to put myself in the patient's shoes'. Dr 17, GP

'I did give up my out-of-hours work. I spend more time within the surgery doing thing like medication reviews, running audits, so all sorts of other things that feels more relaxed'. Dr 33, GP

'I'm more proactive at calling them and see how they are and making sure that they know they have got their results. That reduces my risk of missing results'. Dr 60, GP

'I changed my practice a little bit a result of that, for consent to be more inclusive even of less common complications of procedures that I might otherwise have just discounted'. Dr 64, consultant

'The one thing that I learnt is to always make sure that the patient is happy with your treatment plan and they understand that'. Dr 1, GP

'I've lost that exponential relationship of adverse events to the busyness of my practice'. Dr 64, Consultant

'I was working hard, probably too hard. But since last August, no private practice, it's been great'. Dr 53, Consultant

'We used to be 8 partners and then we went down to 6 , then we went down to 5, then we down to 4'. Dr 14, GP

' ...the proof of the pudding is that in the twoyears since I've engaged, I've had only one incident that I'm aware of that might go somewhere...'. Dr 64, Consultant

'If you don't explain to them that look, we really do want to make your system safer, it almost, sort of, feels like an investigation'. Dr 36, GP

'I think the CCP will dramatically reduce my risk of future claim or pre-claim. I think the Member Risk Review might reduce the risk of a successful suit'. Dr 35, GP

'We weren't doing anything horrendously wrong...'. Dr 14, GP

process and implication

relevance of MRR process to self

- sharing report findings with others

3. Feedback and proposals

- perceptions of the MPS MRR facilitator

- perceptions of MRR usefulness

- members suggestions to improve the MRR process.

\begin{abstract}
'Helpful, wise, experienced, very approachable, friendly, head teacher, lovely chap, personable, professional, pastoral, identify with, neutral, not intimidating'. 'He seemed to understand the issues very well. He seemed to be a wise person, who has obviously done it before, and I think a lot of the issues that relate to good practice or otherwise or common sense really. Sometimes it just requires an older, wiser, practitioner I thought he was very good and very positive and very understanding and not actually critical in a negative sense, it was all positive criticism'. Dr 64, Consultant

'I don't think anyone really looks forward to a CQC inspection, but we do'. Dr 33 , GP

'I think if it's seen as supportive, it's actually very good'. Dr 28, GP

'Make booking website simpler to use, they ought to find a way to prioritise booking on workshops'. Dr 35, GP
\end{abstract}

GP, general practitioner; MPS, Medical Protection Society; MRR, Member Risk Review.

changes they had made resulted in improvements to their working and personal lives. They were also able to report a reduced number of medicolegal cases during this period. The doctors interviewed expressed a range of different changes in circumstances from the time when the MRR was conducted and completed. Many of the GPs described changes to their practices such as partners leaving or having to cover absences due to sickness. For the doctors involved, it was apparent that many had to deal with personal/professional circumstances that were happening, most of which they had little control over for example, family bereavement or loss of a partner in the practice.

For most participants, the RE experience led to some form of change in how they worked or behaved, although it was difficult to determine if a change or transition was explicitly linked to the RE process. For example, it was apparent that some doctors had reportedly been considering making changes to how they worked, and the RE was a catalyst to help them make this change. Of the consultants who undertook private practice, three out of four indicated that they had reduced their clinical workloads since the RE process.

\section{Comprehension and validity of RE interventions}

It was clear that the doctors' initial views about the RE process were potentially misconstrued in that it was perceived in negative terms as a professional investigation, rather than educational development. After MRR 
Table 4 Participating GP doctors reported key recommended actions grouped as examples

\begin{tabular}{llll} 
Key recommended action & $\begin{array}{l}\text { Completed } \\
\text { (ID number) }\end{array}$ & $\begin{array}{l}\text { Not completed Barriers for non- } \\
\text { (ID number) }\end{array}$ & $\begin{array}{l}\text { completion } \\
\text { con }\end{array}$ \\
\hline $\begin{array}{l}\text { Review and update repeat prescribing policies } \\
\text { Improve processes for conducting significant event } \\
\text { audits }\end{array}$ & $1,7,17,33,34,35,36$ & $17,31,34,35,54$ & \\
$\begin{array}{l}\text { Use electronic workflow systems so that all activities } \\
\text { required by letters, telephone and messages are } \\
\text { completed, and there is an audit trail of the actions taken }\end{array}$ & $1,7,29,33,35$ & $17,28,3133$ & $\begin{array}{l}\text { Delays in the practices } \\
\text { installing computer } \\
\text { system to record all } \\
\text { messages }\end{array}$
\end{tabular}

Improve processes for recording consent $\quad 16,34,51,54$
$\begin{array}{ll}\text { Improve record keeping, in particular recording of safety } & 17,35,51 \\ \text { netting advice }\end{array}$

netting advice

\begin{tabular}{|c|c|c|c|}
\hline Record the use of chaperones in the medical records & $14,16,36$ & 51 & $\begin{array}{l}\text { Not always offered } \\
\text { chaperone for male } \\
\text { patients }\end{array}$ \\
\hline Update practice leaflet & $18,31,34$ & & \\
\hline Maintain control over personal workload & 54,60 & 18,34 & $\begin{array}{l}\text { Unable to recruit extra } \\
\text { doctors/nurses }\end{array}$ \\
\hline
\end{tabular}

$\begin{array}{ll}\text { Ensure all indemnity arrangements in place } & 33,51 \\ \text { Change and implement practice policy for handling test } & 14\end{array}$

results more safely

\begin{tabular}{|c|c|}
\hline $\begin{array}{l}\text { Ensure practice protocols are dated reviewed and old } \\
\text { ones archived }\end{array}$ & 34 \\
\hline $\begin{array}{l}\text { Change pattern of working out of hours at night to } \\
\text { ensure not working the next day }\end{array}$ & 1 \\
\hline $\begin{array}{l}\text { Attend recommended group sessions for personal health } \\
\text { reasons }\end{array}$ & 16 \\
\hline $\begin{array}{l}\text { To continue locum work safely, focus work on GP } \\
\text { surgeries that have worked at before }\end{array}$ & 16 \\
\hline $\begin{array}{l}\text { Design system to make sure certain medications } \\
\text { required to treat medical emergencies in the community } \\
\text { are to hand }\end{array}$ & 29 \\
\hline Review confidentiality issues relating to text messaging & 35 \\
\hline $\begin{array}{l}\text { Introduce use of voice-activated dictation software to } \\
\text { speed up the process of electronic record keeping }\end{array}$ & 51 \\
\hline
\end{tabular}

GP, general practitioner.

participation and receiving their actionable recommendations for the next 6-9 months, participants were reportedly better able to understand how to manage their working practices more effectively, although it was difficult to determine if a change or transition was explicitly linked to the RE process. For example, it was apparent that some doctors had reportedly been considering making changes to how they worked, and the RE was a catalyst to help them make this change. It also provided a degree of reassurance for some in terms of highlighting specific working issues and how these could be addressed at the individual (eg, reducing out-of-hours working commitments) and practice levels (eg, improving systems for managing test results, specialist referrals or repeat prescribing).

A diverse range of views was expressed around why things had gone wrong in many of the medicolegal cases related to the participants, and the relevance and need for participation in the RE process. A common theme was that there may be potential care system risks that contributed to performance and that these could be reduced. However, the cases were very varied in terms of impact to patient and doctor in how, why and when they had occurred and the nature and scale of professional responsibilities involved (or otherwise).

Participants were able to describe how some of the system risks highlighted were directly related to their work as individual clinicians, including their wider organisation and management of the GP surgery (or private hospitals where consultants worked). However, while some GPs expressed views that their practice manager would address all risks related to organisational issues, others felt that it was relevant for them to take more professional ownership of all practice identified risks. 
Table 5 Participating consultant doctors reported key recommended actions grouped as examples

\begin{tabular}{|c|c|c|c|}
\hline Key recommended action & $\begin{array}{l}\text { Completed } \\
\text { (consultant ID number) }\end{array}$ & $\begin{array}{l}\text { Not completed } \\
\text { (consultant ID number) }\end{array}$ & Barriers for non-completion \\
\hline $\begin{array}{l}\text { Improve processes for recording } \\
\text { consent }\end{array}$ & 53,64 & & \\
\hline
\end{tabular}

Ensure all indemnity arrangements in 39,53

place

$\begin{array}{ll}\text { Improve record keeping, in particular } & 64 \\ \text { recording of safety netting advice } & \\ \text { Improve processes for conducting } & 77\end{array}$

significant event audits

\begin{tabular}{|c|c|c|c|}
\hline $\begin{array}{l}\text { Record the use of chaperones in the } \\
\text { medical records }\end{array}$ & 77 & 64 & $\begin{array}{l}\text { Always had a chaperone so did } \\
\text { not record in medical records }\end{array}$ \\
\hline Maintain control over personal workload & 53 & 64 & Unable to recruit secretary \\
\hline $\begin{array}{l}\text { Ensure practice protocols are dated } \\
\text { reviewed and old ones archived }\end{array}$ & 39 & & \\
\hline
\end{tabular}

Use standard preoperative consent forms/equipment

$39,64,77$ 39

Removed information displayed on
website without patient consent

Ensured reservations of surgical facilities at private hospital

\begin{tabular}{|c|c|c|c|}
\hline $\begin{array}{l}\text { Have a well-advertised complaints } \\
\text { procedure for patients and families }\end{array}$ & 39 & & \\
\hline Offered timely follow-up consultations & 53 & 53 & $\begin{array}{l}\text { Partially met, dependent on } \\
\text { length of NHS waiting lists }\end{array}$ \\
\hline Completed child protection training & 53 & & \\
\hline
\end{tabular}

NHS, National Health Services.

Most also described a degree of usefulness in sharing part or most of their report recommendations with practice managers and medical appraisers, thereby demonstrating that learning and improvement related to the RE process was valued and had wider implications. Some, however, worked in single-handed practices or independent private consultants and did not feel able to share the report findings.

\section{Feedback and proposals}

The MPS Clinical Risk Facilitators who undertook the MRR intervention were strongly perceived as being supportive and compassionate. The MRR in particular was seen as being useful in a number of ways. Most of the doctors reported that they had completed the recommendations within a 6-month period. They felt to some extent that this would make the practice safer. A common theme (for those doctors based in England) was that this process was helpful in preparation for a Care Quality Commission inspection, which was an unexpected but very positive finding.

Based on professional experiences of the RE process, the doctors interviewed made a wide range of suggestions for improvement for MPS to consider. For example, that the supportive nature of the educational interventions should be much clearer at initial contact; fuller and more detailed explanations of the RE processes should be available and accessible; and continuing professional development credits should be available for completing the MRR. Reflecting on the study findings and the suggestions from participants led the MPS faculty to develop an integrated list of recommendations to enhance the overall RE process (box 2).

\section{DISCUSSION}

The study met its stated objectives of exploring the experiences of medical doctors with significantly more medicolegal cases than their peers, who participated in a risk educational process that aimed to reduce future risks and impacts for patients and doctors. Given the largely positive feedback collated and the volume of reported improvement actions undertaken or committed to, most participants appeared to value all the RE interventions they completed to some extent, which provides important information into their potential effectiveness and impact on reducing risks and enhancing well-being. This offers MPS and others with similar educational programmes some evidence of the learning and improvement impacts 
Box 2 Enhancements to risk education (RE) processes recommended by study participants and Medical

Protection Society (MPS) faculty

\section{MPS education services}

- The MRR should be managed as a 6-month programme where the measured outcomes are related to the completed recommended actions, as reported by the member.

- MPS should consider providing continuous professional development credits for completion of MRR recommended actions.

- Improve administrative systems to make it easier and more accessible for members to book onto MPS workshops.

- Explore whether the educational remediation principles underpinning the MRR process could be strengthened and made more explicit to all stakeholders, for example, facilitators and participants.

- The findings of this study have been fed back to the MPS Education clinical risk facilitators as a validation and affirmation of their successful working approaches with members at a sensitive time.

\section{Wider MPS Support}

- It is important to acknowledge the emotional impact that medicolegal cases can have on members. Some members may benefit from accessing the MPS counselling service.

- Consideration should be given to ways to improve members understanding of the proposed educational interventions. Ensure messaging received by members is clear that educational interventions are highly supportive and developmental and not punitive.

- Consideration as to whether the MRR intervention should be offered to (or tested with) other healthcare professional, for example, dentists.

of these types of interventions. Additionally, participants provided important feedback on how the RE process could be better improved to enhance the educational experience and reduce any anxieties for other participants in the future.

Participation in the RE processes reportedly led to positive changes in attitudes and behaviours and, importantly, actions to improve performance and well-being and potentially reduce risks for themselves and patients. To our knowledge, this is one of the first qualitative evaluations of educational interventions aimed at reducing medicolegal risks in a group of medical doctors with significantly more medicolegal cases than their peers.

We know from previous MPS CCP research that the numbers of claims against participants were reduced following undertaking the intervention, ${ }^{28}$ while participation also resulted in a more positive attitude towards patient-centred care and a change in consultation behaviours. $^{31}$

For most participants, there was gradual acceptance that elements of their professional practice and related organisational arrangements were contributing negatively to individual performance and well-being for themselves and some of their patients, resulting in increased medicolegal cases from patients and families.

Related consequences such as feelings of anger and embarrassment, were all reported, which mirrors previous research. ${ }^{6}$ Additional personal, family issues and wider systemic problems were also recognised by some participants after the RE process as influencing performance such as inadequate communication skills, relationships with colleagues, practice arrangements and unsafe medicines management. This provides evidence of insight and willingness to accept these issues and, as reported, take corrective actions to reduce risks. ${ }^{22}$

Previous studies highlight factors that increase the risk of patients taking action against a doctor such as rudeness, delays, inattentiveness, lack of empathy and compassion, bullying, arrogance, apathy, disorganisation, miscommunication and failure to communicate. ${ }^{32-34}$ Inability to cope with workloads, dysfunctional team working, weak record keeping, poor decision making and serious deviations from protocols are also highlighted as significant risks. ${ }^{1}$ Older, male doctors ( $>50$ years) predominated in our participation group that mirrors much of the evidence in this area for underperforming practitioners. ${ }^{1-6}$ As this group may have had greater exposure to risk and as senior doctors may see more complex patient cases, then a more tailored educational intervention might be needed to support them. Perhaps unsurprisingly most of these issues were raised in the medicolegal cases made by patients and others against the doctors participating in this study.

The evaluation was also insightful in terms of reviewing and improving the design, content and delivery of the RE programme as a combined means of risk identification and providing educational support. However, the findings may also have some wider meaning and implications for the medical education evidence base; medical appraisal and educational research; healthcare employers and responsible officers for revalidation; policymakers; and the GMC.

Medicolegal cases made by patients and families are of great value in providing important scrutiny of care quality issues, particularly those around patient safety and the patient experience. The findings from this study add to the existing but limited knowledge in this area; however, there is also a strong acknowledgement that this is a highly complex area, and it is difficult to provide predictive 'proof' of association or correlation between the RE interventions and future risk reduction outcomes without long-term monitoring and follow-up.

The experience and perception of many doctors in this study was that being invited to the RE process was not indicated as they felt they were no different from their peers in the of number of medicolegal cases experienced. When viewed at the population level of doctors, the evidence strongly contradicts this perspective given that a relatively small proportion of the workforce accounts for a significant number of medicolegal cases. ${ }^{12} 63435$ When the doctors in the study engaged with the education, in particular the MRR, their perception of being no different from their peers changed to an acceptance that they had different medicolegal risk. 


\section{Study strengths and limitations}

The use of semistructured telephone interviews enabled detailed exploration of areas that were important to the participating doctors. As more interviews were conducted and the transcripts were analysed, the focus of the questioning was modified, and the main themes emerging were also confirmed until limited new information was being obtained, and hence we were confident that data saturation was reached. Data analysis was undertaken independently by one internal and one external researcher. The internal researcher had no involvement in the selection of doctors or delivery of the interventions to limit bias. The doctors were interviewed at least 6 months after the intervention and were able to report changes/transitions in their behaviours and circumstances, but recall bias may also have been an issue.

Study participants were provided with clear information explaining that the recording was confidential and would be anonymised. They were also informed that the MPS services and benefits they receive will continue and nothing will change. It is possible that the interviewees provided responses that they felt would be viewed favourably by the lead researcher (social desirability bias). The interviewees were made aware that $\mathrm{JJ}$ was an employee of MPS but not involved at the time of their participation in the RE process. The field notes collected by the interviewer were shared during the process of thematic analysis. Independent review of the field notes demonstrated that there were a range of emotions expressed by the interviewees. The authors felt following the analysis of transcripts and field notes that the steps taken to encourage interviewees to be fully open and forthright about their experiences and views were probably effective.

A key study objective was to explore and describe the self-reported performance improvements (eg, changed attitudes or modified behaviours) associated with the RE intervention. We fully acknowledge that the self-reported changes in attitudes, behaviours and related improvements in practice cannot be fully verified, and therefore we should be cautious about the strength this type of 'evidence' to support the 'impact' of such an educational intervention as it would be considered weak evidence overall.

The age, gender, specialty and number of medicolegal cases were similar for study participants compared with those who did not volunteer to be interviewed. A convenience sampling strategy was agreed for pragmatic reasons that is, we interviewed all 20 doctors who contacted us. This is a limitation as it is unlikely to reflect the characteristics and experiences of all RE participants-a more purposive sampling strategy may have added rigour in that regard, but we judged that more volunteers would have been required for this purpose. We do know, however, that the gender and age profiles of our study sample were similar to the larger population of RE participants.

There is a significant gender inequity in our sample; this may be partly explained by the MPS membership of general medical practitioners and hospital specialists having a higher proportion of male members (58.2\%). Furthermore, in the UK and Ireland, there is a greater gender inequity among older clinicians, favouring men. Older, male doctors ( $>50$ years) predominated in our participation group, which mirrors much of the evidence in this area for underperforming practitioners. ${ }^{13-6} \mathrm{~A}$ previous study has indicated that medical doctors involved in medicolegal matters were more likely to be working longer hours than those who were not involved. ${ }^{18} \mathrm{~A}$ comparison was not made between male and female doctors of the number of hours worked. It is postulated that older male members generally work longer hours than females, and this may have been another factor that led to a gender inequity in the sample.

It is also possible that the doctors felt they had to report completion of recommended actions due to nature of the interview or implications with future contact with MPS. Study findings are limited to the views and perceptions of those interviewed, while the sample was voluntary, and no formal sample selection process was used for pragmatic reasons of increasing participation levels. It is possible that face-to-face interviews and/or a questionnaire survey may have elicited more in-depth responses or augmented the study findings. MPS provides indemnity cover for general medical practitioners and doctors in private practice. Finally, we acknowledge that the interviewees were asked some questions of a sensitive nature. The field notes demonstrated that those interviewed expressed favourable and unfavourable feelings about the RE process. Some of the responses may have been phrased in a way that the interviewees would have felt the researcher wanted to hear.

There is increasing concern worldwide about the rising numbers of claims for clinical negligence. Identifying and remediating those doctors whose performance gives cause for concern is critical for care quality and safety. ${ }^{20}{ }^{21}$ The underlying nature of poor performance among hospital specialists and family doctors is established as being multifaceted. ${ }^{22}$ Medical remediation of doctors refers to a complex process of addressing performance concerns (knowledge, skills and behaviours).

This study has enhanced our understanding of providing a remediation programme. The participants in the programme were selected by MPS as having significantly more medicolegal cases than their peers. The recruitment focus was on doctors who were identified as having inadequate practice arrangements, for example, unsafe medication prescribing and poor management of test results. Many also had evidence of poor communication skills. The sample was predominately older, male, senior doctors with many years of experience.

By using qualitative interviews, we were able to explore in depth the doctors' views on what worked well and areas to improve. Overall, the support provided and non-judgemental nature of the clinical risk facilitators were seen as an important component to the success of the programme. As the underlying factors leading to poor performance were varied, we were able to tailor the RE programmes to meet the individual needs. It was apparent that many 
of the doctors in the sample worked in stressful environments and had suffered the additional stresses of dealing with medicolegal issues, some for many years. The remediation programme resulted in doctors self-reporting changes in working practices and behaviours. It is clear that there are many factors that influence change in practice; it can be sometimes difficult to know the extent to which any remediation might affect this change.

There can be challenges to providing remediation in particular to more experienced clinicians as we feel they may question the selection process and also the validity of the interventions. This study highlighted that the initial contact about a remediation programme can elicit a mixture of responses. Providing a clear purpose and outcome objectives at the outset are important components. The interviewees had some initial concerns; however, once they had completed the interventions and had time to reflect on the changes they had made, the majority were grateful that they were given the opportunity to review their practice.

\section{Future research}

A long-term (3 to 5years) follow-up study of members' rates of multiple claims or disciplinary actions following MPS educational interventions is planned to provide further evidence of success or otherwise. A comparison would also be made with rates of cases before any educational intervention. Similarly, a further area for future research would be around following up this group of doctors to assess how long any reported positive outcomes persisted.

\section{CONCLUSIONS}

The MPS RE process was largely valued by participants, all of whom were practising in changing and pressured clinical environments. Medicolegal cases against doctors can be very complex and often go beyond fundamental personal behavioural problems or issues of clinical skill, knowledge and competence. A wide range of human interactions with wider system factors may be at play, alongside professional and personality issues, and these can be difficult to identify, understand and disentangle. Issues such as performance and communication styles, differences in job content, patient and illness-related factors, organisation of work, education and training, workload and practice responsibilities all require further study to clarify what can be important in influencing the odds of involvement in medicolegal cases. ${ }^{18}$ Overall, the $\mathrm{RE}$ process was largely valued by participants with many reporting that participation led to some positive professional behaviour changes, improvements in practice processes and personal well-being.

Acknowledgements We would like to offer sincere thanks to those medical doctors who participated in this study and who openly shared their experiences of and opinions on the RE process and also gave freely of their personal time.

Contributors $\mathrm{JJ}$ conceived and led the study, collected and analysed data and codrafted the manuscript. PB codesigned and co-led the study, analysed and interpreted data and codrafted the manuscript. JP, MM and MD all checked data, provided professional insights into the design and area of study and contributed to the development and critical appraisal of the manuscript.

Funding This research received no specific grant from any funding agency in the public, commercial or not-for-profit sectors.

Competing interests None declared.

Patient consent Not required.

Ethics approval Under UK 'Governance Arrangements for Research Ethics Committees', National Health Service (NHS) ethical research committee review is not required for service evaluation or research which, for example, seeks to elicit the views, experiences and knowledge of NHS health care professionals on a given subject area and who are recruited as study participants by virtue of their professional roles.

Provenance and peer review Not commissioned; externally peer reviewed. Data sharing statement No additional data.

Open Access This is an Open Access article distributed in accordance with the Creative Commons Attribution Non Commercial (CC BY-NC 4.0) license, which permits others to distribute, remix, adapt, build upon this work non-commercially, and license their derivative works on different terms, provided the original work is properly cited and the use is non-commercial. See: http://creativecommons.org/ licenses/by-nc/4.0/

(C) Article author(s) (or their employer(s) unless otherwise stated in the text of the article) 2018. All rights reserved. No commercial use is permitted unless otherwise expressly granted.

\section{REFERENCES}

1. Donaldson LJ, Panesar SS, McAvoy PA, et al. Identification of poor performance in a national medical workforce over 11 years: an observational study. BMJ Qual Saf 2014;23:147-52.

2. General Medical Council. The state of medical education and practice in the UK. London, UK: General Medical Council, 2016.

3. Bismark MM, Spittal MJ, Gurrin LC, et al. Identification of doctors at risk of recurrent complaints: a national study of healthcare complaints in Australia. Quality and Safety in Health Care 2013. doi: 10.1136/bmjqs-2012-001691 [Epub ahead of print $10 \mathrm{Apr}$ 2017].

4. Studdert DM, Bismark MM, Mello MM, et al. Prevalence and Characteristics of Physicians Prone to Malpractice Claims. N Engl J Med 2016;374:354-62.

5. Medical Protection Society. $88 \%$ of GPs believe they are more likely to be sued now than five years ago. $2015 \mathrm{https}: / / \mathrm{www}$. medicalprotection.org/uk/for-members/press-releases/pressreleases/88-of-gps-believe-they-are-more-likely-to-be-sued-nowthan-five-years-ago (accessed $19 \mathrm{Jul}$ 2017).

6. Bourne T, Wynants L, Peters M, et al. The impact of complaints procedures on the welfare, health and clinical practise of 7926 doctors in the UK: a cross-sectional survey. BMJ Open 2015;5:e006687.

7. Cohen D. Measuring a doctor's performance: personality, health and well-being. Occup Med 2006;56:438-40.

8. Cunningham $W$. The immediate and long-term impact on New Zealand doctors who receive patient complaints. $N Z$ Med J 2004;117:U972.

9. Dowell AC, Hamilton S, McLeod DK. Job satisfaction, psychological morbidity and job stress among New Zealand general practitioners. N Z Med J 2000;113:269-72.

10. Chamberlain JM. The hearing of fitness to practice cases by the General Medical Council: Current trends and future research agendas. Health Risk Soc 2011;13:561-75.

11. Bismark MM, Spittal MJ, Studdert DM. Prevalence and characteristics of complaint-prone doctors in private practice in Victoria. Med J Aust 2011;195:25-8.

12. Hickson GB, Federspiel CF, Pichert JW, et al. Patient complaints and malpractice risk. JAMA 2002;287:2951-7.

13. Humphrey C, Hickman S, Gulliford MC. Place of medical qualification and outcomes of UK General Medical Council "fitness to practise" process: cohort study. BMJ 2011;342:d1817.

14. Jena $A B$, Seabury $S$, Lakdawalla $D$, et al. Malpractice risk according to physician specialty. N Engl J Med 2011;365:629-36.

15. Khaliq AA, Dimassi H, Huang CY, et al. Disciplinary action against physicians: who is likely to get disciplined? Am J Med 2005;118:773-7. 
16. Kohatsu ND, Gould D, Ross LK, et al. Characteristics associated with physician discipline: a case-control study. Arch Intern Med 2004;164:653-8.

17. Birkeland S, Depont Christensen R, Damsbo N, et al. Characteristics of complaints resulting in disciplinary actions against Danish GPs. Scand J Prim Health Care 2013;31:153-7.

18. Nash LM, Kelly PJ, Daly MG, et al. Australian doctors' involvement in medicolegal matters: a cross-sectional self-report study. Med J Aust 2009;191:436-40.

19. Matthews $P$, Beech M, Rhydderch M, et al. A New Model of Educational Provision for GPs Directed to Undertake Further Training in Wales. Education for Primary Care 2007:18:316-27.

20. Panesar SS, deSilva D, Carson-Stevens A, et al. How safe is primary care? A systematic review. BMJ Qual Saf 2016;25:544-53.

21. Williams BW. The prevalence and special educational requirements of dyscompetent physicians. J Contin Educ Health Prof 2006;26:173-91.

22. Vincent $\mathrm{C}$, Woloshynowych $\mathrm{M}$. The assessment of performance, Annex A. An analysis of general practitioner cases referred to the General Medical Council following the introduction of performance procedures. London, UK: General Medical Council, 2002.

23. Castledine SG. Dealing with difficult doctors. Br J Nurs 2008;17:1305.

24. Norfolk T, Siriwardena AN. A comprehensive model for diagnosing the causes of individual medical performance problems: skills, knowledge, internal, past and external factors (SKIPE). Qual Prim Care 2013;21:315-23.

25. Swanwick T, Whiteman J. Remediation: where does the responsibility lie? Postgrad Med J 2013;89:1-3.
26. Cleland J, Leggett $\mathrm{H}$, Sandars $\mathrm{J}$, et al. The remediation challenge: theoretical and methodological insights from a systematic review. Med Educ 2013;47:242-51.

27. Society MP. Important information for GPs in England. https://www. medicalprotection.org/uk (accessed $18 \mathrm{Jul}$ 2017).

28. O'Brien M, Dinwoodie M, Hartwig B, et al. The Clinical Communication Programme; an effective intervention for reducing future risk for high risk physicians. Asia Pac J Public Health Care Manage 2014;9:8-13.

29. Smith EM. Telephone interviewing in healthcare research: a summary of the evidence. Nurse Res 2005;12:32-41.

30. Saldana J. The Coding Manual for Qualitative Researchers. CA: Sage: Thousand Oaks, 2009.

31. Warwick Medical School. Report for Medical Protection Society on Clinical Communication Programme. London: Medical Protection Society Ltd, 2014.

32. Bunting RF, Benton J, Morgan WD. Practical risk management principles for physicians. J Healthc Risk Manag 1998;18:29-53.

33. Press I. The Predisposition to File Claims: The Patient's Perspective. Law, Medicine and Health Care 1984;12:53-62.

34. Stephen F, Melville A, Krause T. A Study of Medical Negligence Claiming in Scotland. School of Law, University of Manchester. http:// www.gov.scot/Resource/0039/00394482.pdf. (accessed 24 Jul 2017).

35. Wallace E, Lowry J, Smith SM, et al. The epidemiology of malpractice claims in primary care: a systematic review. BMJ Open 2013;3:e002929. 